\title{
Complex aortic valve repair as a durable and effective alternative to valve replacement in children with aortic valve disease
}

\author{
James S. Tweddell, MD $D^{a, b}$ \\ Andrew N. Pelech, MD ${ }^{a, c}$ \\ Peter C. Frommelt, MD ${ }^{\mathrm{a}, \mathrm{c}}$ \\ Robert D. B. Jaquiss, MD ${ }^{a, b}$ \\ George M. Hoffman, MD ${ }^{d}$ \\ Kathleen A. Mussatto, $\mathrm{RN}^{\mathrm{a}}$ \\ S. Bert Litwin, $M D^{\mathrm{a}}$
}

From Herma Heart Center, Children's Hos-
pital of Wisconsin, ${ }^{\mathrm{a}}$ and the Division of
Cardiothoracic Surgery, Department of
Surgery, ${ }^{\mathrm{b}}$ Division of Pediatric Cardiology,
Department of Pediatrics, ${ }^{\mathrm{c}}$ and Department
of Anesthesia, ${ }^{\mathrm{d}}$ Medical College of Wis-
consin, Milwaukee, Wis.

Read at the Thirtieth Annual Meeting of The Western Thoracic Surgical Association, Maui, Hawaii, June 23-26, 2004.

Received for publication June 21, 2004; revisions received Sept 7, 2004; accepted for publication Sept 21, 2004.

Address for reprints: James S. Tweddell, MD, Chair Cardiothoracic Surgery, Children's Hospital of Wisconsin, MS 715, $9000 \mathrm{~W}$ Wisconsin Ave, Milwaukee, WI 53226 (E-mail: jtweddell@chw.org).

J Thorac Cardiovasc Surg 2005;129:551-8 $0022-5223 / \$ 30.00$

Copyright $\odot 2005$ by The American Association for Thoracic Surgery

doi:10.1016/j.jtcvs.2004.09.033
Objective: This study was undertaken to determine the utility of aortic valve repair in children.

Methods: A retrospective analysis was conducted on aortic valve surgery from 1973 to 2004 at Children's Hospital of Wisconsin.

Results: Procedures were classified as simple repairs (blunt valvotomy, commissurotomy with or without thinning, $\mathrm{n}=147$ ), repair of aortic insufficiency with ventricular septal defect $(n=22)$, complex repairs (any combination of additional procedures including suspension of prolapsed leaflets, leaflet extensions, repair of torn or perforated leaflets, annuloplasty, reduction of sinus of Valsalva plasty, and concomitant repair of supravalvular or subvalvular stenosis, $n=57$ ), and replacements ( $\mathrm{n}=57,20$ mechanical, 2 porcine, and 35 human valves). Freedoms from reintervention for simple repairs and repair of aortic insufficiency with ventricular septal defect at 10 years were $86 \% \pm 5 \%$ and $93.3 \% \pm 6 \%$, respectively. For complex valve repair, freedoms from reintervention at 1,5 , and 10 years were $94 \%$ $\pm 3 \%, 85 \% \pm 6 \%$, and $44 \% \pm 15 \%$, versus $96 \% \pm 3 \%, 77 \% \pm 9 \%$, and $77 \% \pm$ $9 \%$ for valve replacement $(P=.3)$. At intermediate follow-up, patients with complex valve repair had a residual gradient of $20 \pm 21 \mathrm{~mm} \mathrm{Hg}$, and $94 \%$ were free of severe aortic insufficiency. Residual aortic stenosis $(P<.05)$ but not the preoperative diagnosis of combined aortic stenosis and insufficiency predicted the need for reintervention.

Conclusion: Freedom from reintervention after complex valve repairs was not different from that after valve replacement, with acceptable residual aortic stenosis and insufficiency. Simple repairs and repair of aortic insufficiency with ventricular septal defect yielded excellent long-term freedom from reintervention.

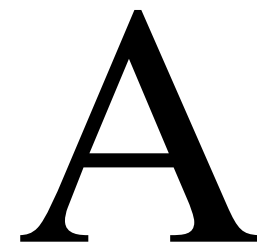

ortic valve replacement options are limited in children. Mechanical valves require anticoagulation, and patients have an ongoing, constant risk of thromboembolic and bleeding complications. ${ }^{1-3}$ Noncompliance with activity restrictions and medical regimens, combined with the high-risk behavior that characterizes adolescence, makes the use of mechanical valves less attractive. ${ }^{4} \mathrm{Al}-$ though aortic homografts result in excellent early hemodynamics, durability is limited in the pediatric population. ${ }^{5,6}$ Neither mechanical valves nor homografts allow for growth, and if valves are not initially oversized in small children, 
patient-prosthetic mismatch will result. The pulmonary autograft, frequently chosen for infants and small children, does allow for growth; however, late dilatation of the neoaortic root with aortic insufficiency (AI) has been identified in a subgroup of patients. ${ }^{7,8}$ Aortic valve repair techniques have evolved slowly and have not yet gained wide acceptance. Nevertheless, techniques that result in satisfactory hemodynamics and acceptable late outcome may provide a reasonable alternative for select patients. Furthermore, valve repair has two important advantages relative to replacement: allowance for growth and avoidance of anticoagulation. We undertook this study to look at our results with aortic valve repair.

\section{Patients and Methods}

The Human Research Review Committee at the Children's Hospital of Wisconsin and Medical College of Wisconsin approved a retrospective chart review of all patients undergoing aortic valve surgery between 1973 and April 2004. Variables included demographic data, pathology leading to aortic valve intervention, and hemodynamic indication for surgery, either aortic stenosis (AS, gradient $>40 \mathrm{~mm} \mathrm{Hg}$ ), AI (at least moderate with AS $<40 \mathrm{~mm}$ $\mathrm{Hg}$ ), or combined AS and AI (gradient $>40 \mathrm{~mm} \mathrm{Hg}$ with at least mild AI). End points included death, reintervention on the aortic valve, and late function as assessed by echocardiography. Peak instantaneous gradients were reported. Insufficiency was graded on a scale of 0 to 3 ( 0 representing none to trivial, 1 representing mild, 2 representing moderate, and 3 representing severe).

The population of interest in the study were patients in whom valve replacement might have been considered a reasonable alternative to valve repair. To this end, we reviewed the records of all 271 patients undergoing aortic valve surgery and classified the procedures into the following categories: simple aortic valve repair, repair of AI with ventricular septal defect (VSD), complex aortic valve repair, and aortic valve replacement.

Simple aortic valve repairs included valvotomy, commissurotomy, and commissurotomy plus leaflet thinning. For this study, valvotomy was defined as blunt dilatation of the stenosed aortic valve and was performed with either inflow occlusion or cardiopulmonary bypass. Commissurotomy was performed under cardiopulmonary bypass with cardioplegic arrest and involved incision of fused commissures under direct vision. Thinning was defined as débridement of thickened leaflets. Repair of AI with VSD was performed as described by either Trusler and colleagues ${ }^{9}$ or Yacoub and associates. ${ }^{10}$

The procedures considered to be complex aortic valve repairs varied, but all were more extensive than commissurotomy with leaflet thinning. They included any combination of additional techniques, including repair of leaflet perforations or tears, leaflet extension, suspension of prolapsed leaflets, annuloplasty, and repair of associated subaortic or supravalvular stenosis. Procedures involving only resection of subaortic narrowing or repair of supravalvular stenosis were not included. Leaflet perforations or tears were repaired either primarily or with autologous or bovine pericardium. Suspension of prolapsed leaflets was accomplished with free edge plication, triangular resection, or commissuroplasty with either autologous or bovine pericardium as described by Monro and colleagues. ${ }^{11}$ Annuloplasty was performed as described by Cosgrove and colleagues. ${ }^{12}$ All procedures were performed with mildly hypothermic cardiopulmonary bypass and cardioplegia.

\section{Statistical Methods}

All data are expressed as mean \pm SD unless otherwise specified. Median values are reported where appropriate. Normally distributed variables were compared with analysis of variance. The Fisher exact test was used for binary variables. Nonnormally distributed variables were compared by the Mann-Whitney test. Univariate logistic regression was used to evaluate the impact of echocardiographic variables on valve repair longevity. KaplanMeier analysis was used to determine freedom from reintervention, with log-rank comparison between groups. SPSS version 11.5 (SPSS Inc, Chicago, Ill) and Stata (Stata Corporation, College Station, Tex) statistical software packages were used to perform the analyses.

\section{Results}

Between 1973 and April 2004, a total of 271 patients underwent surgical procedures for aortic valve disease (Figure 1). In the entire group of 271 patients requiring procedures directed at the aortic valve, there were 22 early deaths; operative survival (to hospital discharge and postoperative day 30 ) was $92 \%$. An additional 5 patients (1.8\%) died late. When considered by era of experience, early mortality was $11.6 \%(8 / 69)$ in the decade 1973 to $1983,13.6 \%(8 / 59)$ in the decade 1984 to 1993 , and $4.2 \%(6 / 142)$ after $1994(P=$ $.02)$.

Simple aortic valve repairs for congenital AS were performed in 147 patients; these included valvotomy $(n=34)$, commissurotomy ( $\mathrm{n}=52$ ), and commissurotomy plus thinning of thickened leaflets $(n=61)$ as the first aortic valve surgical intervention. The average age was $6 \pm 6.3$ years. Among those with simple aortic valve repairs, 62 were neonates with AS. Among the 62 neonates, there were 13 early deaths $(21 \%)$ and 2 late deaths $(3.2 \%)$. Fifteen neonates later underwent additional aortic valve surgery, including aortic valve replacement $(\mathrm{n}=7)$, complex aortic valve repair $(\mathrm{n}=5)$, and simple aortic valve repairs $(\mathrm{n}=3$, with 1 each undergoing valvotomy, commissurotomy, and commissurotomy with leaflet thinning). Among the 85 patients older than 30 days who underwent simple aortic valve repairs, there were 2 early deaths $(2.3 \%)$. For patients undergoing simple aortic valve repairs, freedoms from reintervention were $99 \% \pm 0.8 \%$ at 1 year, $96 \% \pm 2 \%$ at 5 years, and $86 \% \pm 5 \%$ at 10 years (Figure 2 ).

Twenty-two patients underwent repair of AI with VSD. There were no early or late deaths among these patients. There was 1 reoperative valve repair 54 days after the original procedure in 1977, resulting in an actuarial freedom from reintervention of $93.3 \% \pm 6 \%$ at 10 years (Figure 3 ). On follow-up at a mean duration of $4.93 \pm 6.9$ years, $86 \%$ of these patients had AI considered mild or less. 


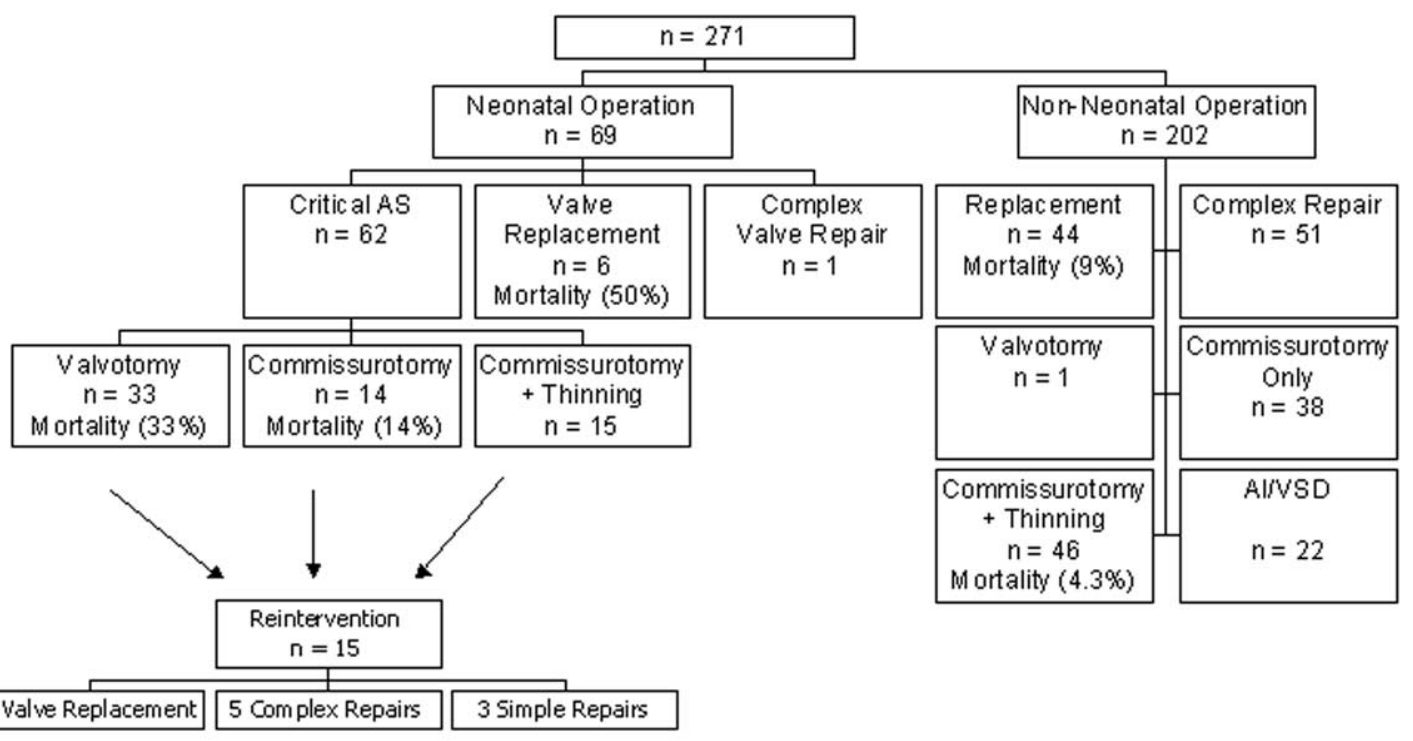

Figure 1. Breakdown of 271 patients undergoing aortic valve surgical interventions at Children's Hospital of Wisconsin from 1973 to 2004.

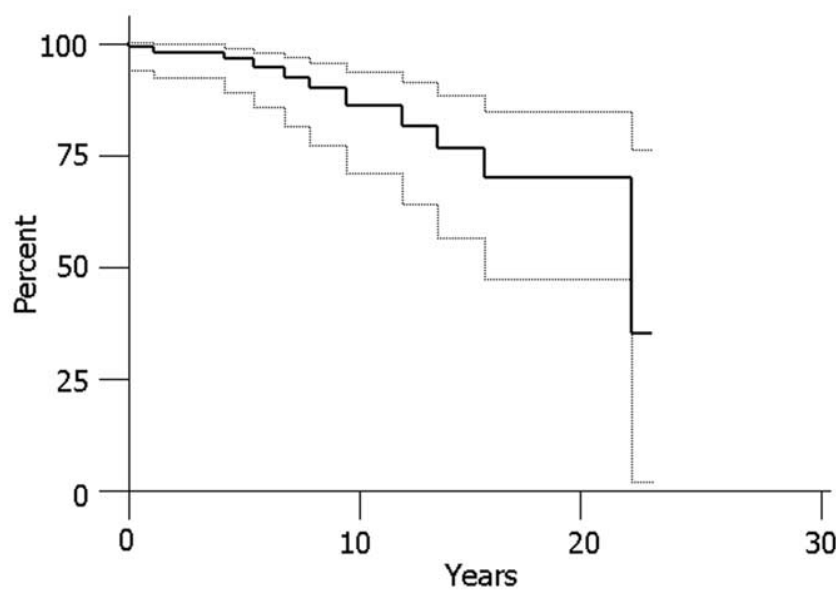

Figure 2. Freedom from reintervention among patients undergoing simple aortic valve repairs, defined as valvotomy, commissurotomy, or commissurotomy and leaflet thinning. Freedoms from reintervention were $99 \% \pm 0.8 \%$ at 1 year, $96 \% \pm 2 \%$ at 5 years, and $86 \% \pm 5 \%$ at 10 years.

The remaining 114 patients underwent aortic valve replacement $(n=57)$ or complex aortic valve repair $(n=57)$. Among patients undergoing aortic valve replacement, the pathologic diagnoses were congenital AS $(\mathrm{n}=33)$, AI from rheumatic heart disease $(\mathrm{n}=9)$ ), AI from endocarditis $(\mathrm{n}=$ 4), AI with other associated congenital heart disease ( $\mathrm{n}=$ 7), AI related to connective tissue disorders $(\mathrm{n}=2)$, and, in the case of 2 patients undergoing valve aortic valve replacement, AI of unknown pathologic cause. At the time of aortic valve replacement, the hemodynamic indications for sur-

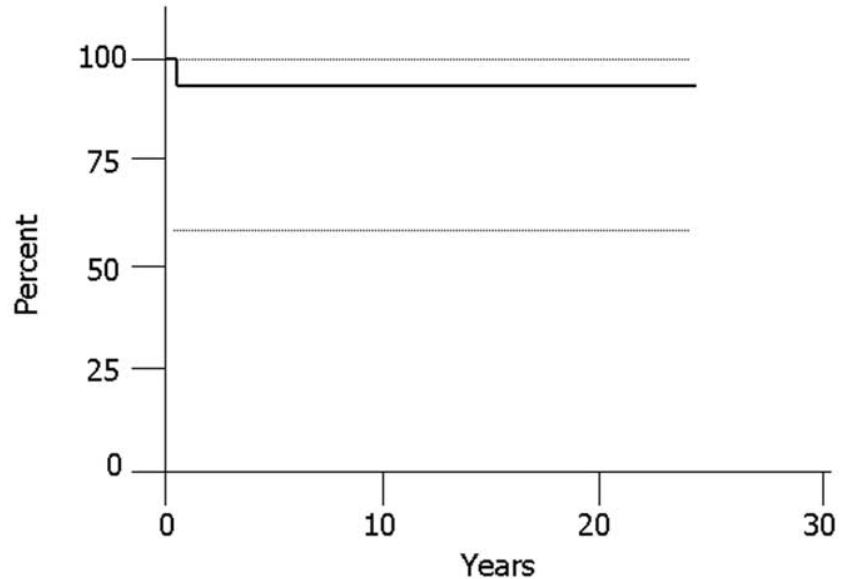

Figure 3. Freedom from reintervention for patients undergoing aortic valve repair for $\mathrm{Al}$ and simultaneous closure of a VSD. Freedom from reintervention was $93.3 \% \pm 6 \%$ at 10 years.

gery were AS $(\mathrm{n}=8), \operatorname{AI}(\mathrm{n}=24)$, and AS with $\mathrm{AI}(\mathrm{n}=$ 25 ). The average age was $12.4 \pm 8.3$ years (range 3 days to 32.7 years). For patients undergoing aortic valve replacement with AS, the preoperative gradient was $52 \pm 34 \mathrm{~mm}$ $\mathrm{Hg}$ (95\% confidence interval [CI] 41-64 mm Hg). For patients undergoing aortic valve replacement with $\mathrm{AI}$, the preoperative degree of insufficiency was $2.4 \pm 1.0$ (95\% CI 2.1-2.7). Mechanical prostheses were used in 20 patients and included 3 St Jude Medical valves (St Jude Medical Inc, Minneapolis, Minn), 5 Björk-Shiley valves (Shiley, Inc, Irvine, Calif), 2 Medtronic Hall valves (Medtronic, Inc, Minneapolis, Minn), and 10 CarboMedics valves (CarboMedics, Inc, Austin, 
TABLE 1. Results of complex aortic valve repair versus valve replacement

\begin{tabular}{lccl}
\hline & Repair & Replacement & $\begin{array}{c}\boldsymbol{P} \\
\text { value }\end{array}$ \\
\hline No. & 57 & 57 & \\
Age at operation (y) & $9.4 \pm 7.9$ & $12.4 \pm 8.3$ & .049 \\
Male (\%) & $74 \%$ & $65 \%$ & .42 \\
Previous valvotomy or & $25 \%$ & $37 \%$ & .20 \\
$\quad$ balloon valvuloplasty (\%) & & & \\
Hemodynamic indication for & & & .06 \\
$\quad$ surgery (\%) & $35 \%$ & $16 \%$ & \\
AS & $32 \%$ & $42 \%$ & \\
Al & $33 \%$ & $42 \%$ & \\
AS and Al & & & \\
Last follow-up & $2.9 \pm 3$ & $3.4 \pm 4$ & .44 \\
$\quad$ Follow-up (y, mean \pm SD) & $20 \pm 21$ & $12.5 \pm 25$ & .10 \\
AS gradient at last follow- & & & \\
$\quad$ up (mm Hg, mean \pm SD) & & $84 \%$ & .07 \\
Al mild or less (\%) & $67 \%$ & $84 \%$ & .72 \\
$\quad$ Al moderate or less (\%) & $94 \%$ & $92 \%$ & \\
\hline
\end{tabular}

Tex). Hancock bioprosthetic valves (Medtronic) were used in two patients. Human valves were used in 35 patients, including aortic homografts in 12 and pulmonary autografts in 23. Procedures to enlarge the left ventricular outflow tract were performed in 16 of 57 patients, including posterior enlargement in 4 patients ( 2 mechanical valves, 1 homograft, and 1 autograft) and aortoventriculoplasty in 12 patients ( 2 mechanical valves, 4 homografts, and 6 autografts). There were 7 early deaths (12.3\%) and 1 late death (1.8\%). Three of the 7 early deaths were neonates, and the remaining 4 nonneonates were 3 patients with endocarditis and 1 patient with severely depressed left ventricular function before valve replacement for severe rheumatic AI. Seven patients with aortic valve replacements have undergone reintervention on the aortic valve, including re-replacement $(\mathrm{n}=6)$ and valve-sparing reconstruction of the autograft root 4 years after the Ross procedure $(n=1)$. Reasons for reintervention on replaced valves included dehiscence of a mechanical valve $(n=1)$, progressive autograft insufficiency $(\mathrm{n}=2)$, homograft degeneration $(\mathrm{n}=$ $2)$, and prosthetic valve endocarditis $(n=2)$.

Among patients undergoing complex aortic valve repair, the pathologic diagnoses were congenital AS $(n=43)$, AI from rheumatic heart disease $(\mathrm{n}=3)$, AI from endocarditis $(\mathrm{n}=1)$, AI associated with other congenital heart disease ( $\mathrm{n}$ $=8)$, AI related to connective tissue disorder $(\mathrm{n}=1)$, and iatrogenic injury of a previously normal valve sustained during an electrophysiologic catheter study $(\mathrm{n}=1)$. At the time of valve repair, the hemodynamic indications for surgery were AS $(\mathrm{n}=20), \mathrm{AI}(\mathrm{n}=18)$, and AS with AI $(\mathrm{n}=$ 19). The average age was $9.4 \pm 7.9$ years (range 11 days to 36.5 years). For patients undergoing complex aortic valve repair with AS, the preoperative gradient was $64 \pm 32 \mathrm{~mm}$ $\mathrm{Hg}$ (95\% CI 54-74 mm Hg). For patients undergoing complex aortic valve repair with AI, the preoperative degree of insufficiency was $1.5 \pm 1.2$ (95\% CI 1.2-1.9). Techniques of valve repair included: commissurotomy $(\mathrm{n}=39,68 \%)$, leaflet thinning $(\mathrm{n}=24,42 \%)$, leaflet suspension $(\mathrm{n}=22$, $39 \%)$, leaflet extension $(\mathrm{n}=3,5 \%)$, repair of tears or perforations $(\mathrm{n}=18,32 \%)$, annuloplasty $(\mathrm{n}=7,12 \%)$, reduction annuloplasty of the sinuses of Valsalva $(\mathrm{n}=1$, $2 \%)$, and repair of concomitant supravalvular $(\mathrm{n}=12,22 \%)$ or subvalvular $(\mathrm{n}=12,22 \%)$ stenosis. Intraoperative assessment of the annular dimension was performed for patients with AS and compared with nomograms. ${ }^{13}$ There were no early deaths and 1 late death among the patients undergoing complex aortic valve repair. Of 57 patients undergoing complex aortic valve repair, 10 have undergone reintervention on the aortic valve; indications were $\mathrm{AI}$ in 5 cases and AS in 5. Reinterventions included 8 valve replacements (4 mechanical, 3 autografts, and 1 homograft), 1 re-repair, and 1 balloon dilatation.

Table 1 summarizes the results of complex aortic valve repair compared with aortic valve replacement. Patients undergoing complex aortic valve repair were slightly younger than patients undergoing replacement $(9.4 \pm 7.9 \mathrm{vs}$ $12.4 \pm 8.3$ years, $P=.049)$. Thirty-five percent (20/57) of patients undergoing valve repair had AS as the primary hemodynamic indication for valve surgery, compared with $16 \%(9 / 57)$ of aortic valve replacement recipients $(P=.06)$. Residual AS at completion of the valve repair was identified as a risk factor for failure of valve repair $(P=.047)$. The preoperative diagnosis of combined AS with AI was not predictive of valve repair failure. Figure 4 shows the freedoms from reintervention for operative survivors of aortic valve replacement and complex aortic valve repair. Freedom from reintervention was not different between the two operative strategies. For complex aortic valve repair, freedoms from reintervention at 1,5 , and 10 years were $94 \% \pm$ $3 \%, 85 \% \pm 6 \%$ and $44 \% \pm 15 \%$, versus $96 \% \pm 3 \%, 77 \%$ $\pm 9 \%$, and $77 \% \pm 9 \%$ for aortic valve replacement $(P=.3)$.

\section{Discussion}

Surgical options for children with aortic valve disease remain limited. The Ross procedure offers the best alternative for small children requiring valve replacement, but there is an ongoing risk of reintervention directed at both the autograft and homograft. Other bioprosthetic valves have limited applicability in children because of rapid degeneration. The durability of mechanical valves is offset by the need for anticoagulation and associated complications, as well as the greater potential for patient prosthetic size mismatch. Valve repair also remains an imperfect solution. Extensive valve reconstructive procedures, such as three-leaflet extension, 
have acceptable early results; long-term results have been disappointing, however, primarily because of a lack of durable bioprosthetic materials that can withstand the forces sustained by normal valve tissue. ${ }^{14-16}$ Nonetheless, valve repair techniques that are straightforward to perform and thus reproducible, use a minimum of prosthetic material, and achieve a satisfactory hemodynamic result would be preferable to valve replacement for selected patients.

For patients with congenital AS with or without AI who have an adequate annular dimension, we have adopted a standardized technique. Commissural fusion is relieved, and leaflets are thinned of fibrous tissue. If an adequate opening can be achieved with a bicuspid valve, we do not proceed to divide the rudimentary commissure or raphe. To prevent prolapse, the leaflets are supported by commissuroplasty as described by Monro and colleagues. ${ }^{11}$ Small triangular patches of pericardium are used to prevent prolapse and reconstruct the commissures without recreating stenosis. Finally, the supravalvular aortic region is augmented as part of the aortotomy closure to relieve any degree of supravalvular aortic narrowing such as commonly occurs with congenital AS (Figure 5). Should there be poststenotic dilatation of the ascending aorta, aneurysmorrhaphy is performed. Most recently, we have chosen bovine pericardium for valve reconstruction (CardioFix bovine pericardium; CarboMedics). This material is highly resistant to calcification, supports growth of host cells, has excellent handling characteristics, and does not require a preimplantation rinse, making it rapidly available. ${ }^{17}$

We evaluated our experience with aortic valve surgery to identify the subgroup of patients who underwent procedures for whom valve replacement was the next best alternative. This required assessment of all patients undergoing aortic valve procedures to exclude simple repairs such as valvotomy, commissurotomy alone, commissurotomy with leaflet thinning, and repair of AI associated with a VSD, because such cases would rarely be considered for immediate valve replacement. We report the results with these noncomplex procedures to confirm their effectiveness and provide a context in which to evaluate complex aortic valve repair and aortic valve replacement.

Although we compared the late results of patients receiving valve replacement with those of patients undergoing valve repair, we recognize that not all patients are candidates for valve repair. The purpose of the comparison between the patients undergoing valve repair and those undergoing valve replacement was to evaluate the repair against the next best alternative. We attempted to identify in this review those patients for whom valve replacement could have been reasonably considered the best alternative.

Any child undergoing aortic valve surgery has a high likelihood of requiring additional intervention directed toward the aortic valve, regardless of whether they undergo

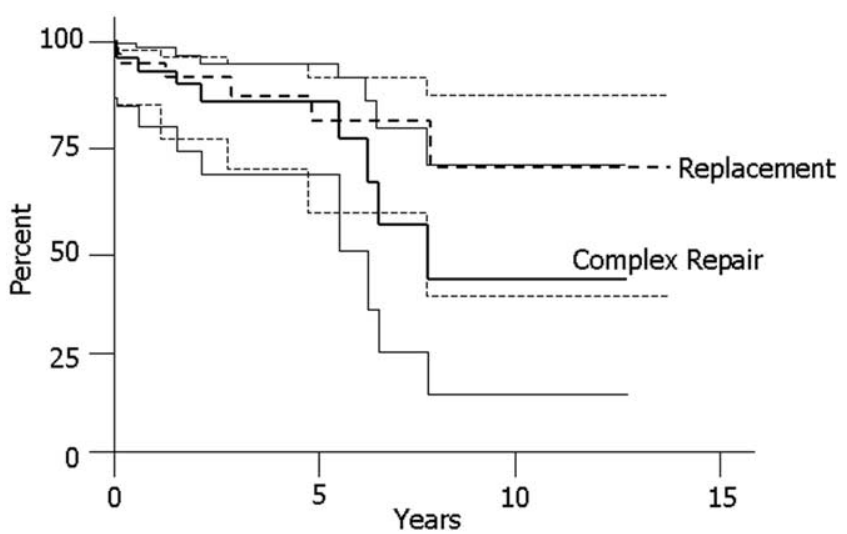

Figure 4. Freedom from reintervention comparing patients undergoing complex aortic valve repair (solid lines) with those undergoing valve replacement (dashed lines). For complex aortic valve repair, freedoms from reintervention at 1, 5, and $\mathbf{1 0}$ years were $94 \% \pm 3 \%, 85 \% \pm 6 \%$, and $44 \% \pm 15 \%$, respectively, versus $96 \%$ $\pm 3 \%, 77 \% \pm 9 \%$, and $77 \% \pm 9 \%$ for valve replacement $(P=.3)$.

repair or replacement. The advantages of valve repair include growth potential, avoidance of anticoagulation, and delay of valve replacement. Furthermore, repair preserves the autograft as a valve replacement option. The disadvantages of valve repair include predictable residual stenosis or insufficiency. Among patients undergoing complex aortic valve repair, the residual gradient at last follow-up was 20 $\pm 21 \mathrm{~mm} \mathrm{Hg}$. Children with aortic valve gradients less than $50 \mathrm{~mm} \mathrm{Hg}$ either without operation or after surgical or balloon intervention have been found to have normal exercise endurance, suggesting that mild residual AS is well tolerated. ${ }^{18}$ The natural history of patients with mild AS (gradient by cardiac catheterization $<25 \mathrm{~mm} \mathrm{Hg}$ ) is good, and more than $90 \%$ are free from operation at 10 years of follow-up. ${ }^{19}$ We speculate that patients with more severe AS who undergo repair with reduction in aortic valve gradient into this range $(<25 \mathrm{~mm} \mathrm{Hg})$ would enjoy a similar outlook. After complex aortic valve repair, $67 \%$ of patients had AI that was mild or less, and $94 \%$ were free of severe AI. The timing of surgery for children with AI remains undefined, and even severe AI can be tolerated for a long time by symptom-free patients. Indices of left ventricular function and dimension provide a more physiologic indication of the need for aortic valve intervention than the degree of AI alone, but it is rare that patients with less than severe AI would undergo valve replacement. ${ }^{20}$

In that subgroup of patients who are candidates for repair, the advantages (growth potential, avoidance of anticoagulation, and minimal thromboembolic risk) and disadvantages (residual lesions and need for later valve surgery) of valve repair must be balanced against the outcome of valve replacement. A recent review of 66 children undergoing the Ross and Ross-Konno procedures found an $85 \%$ 


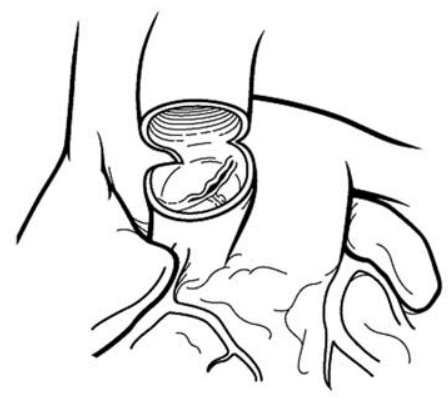

A

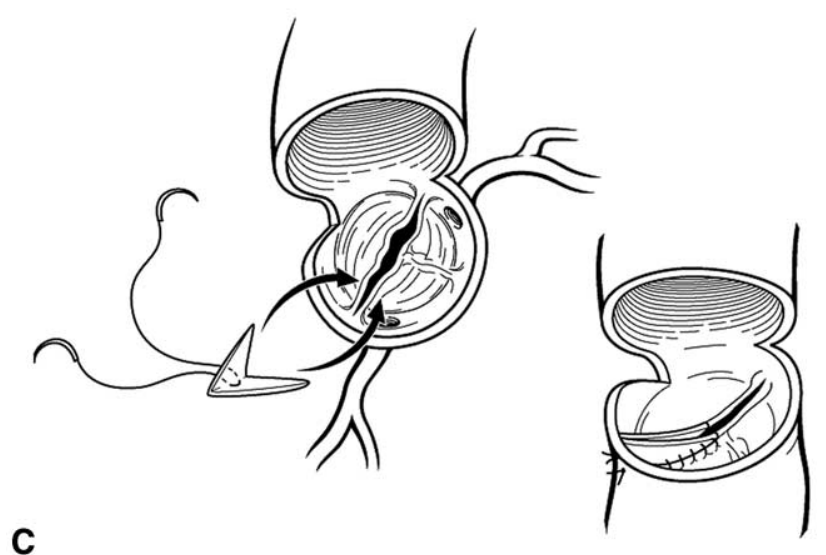

B
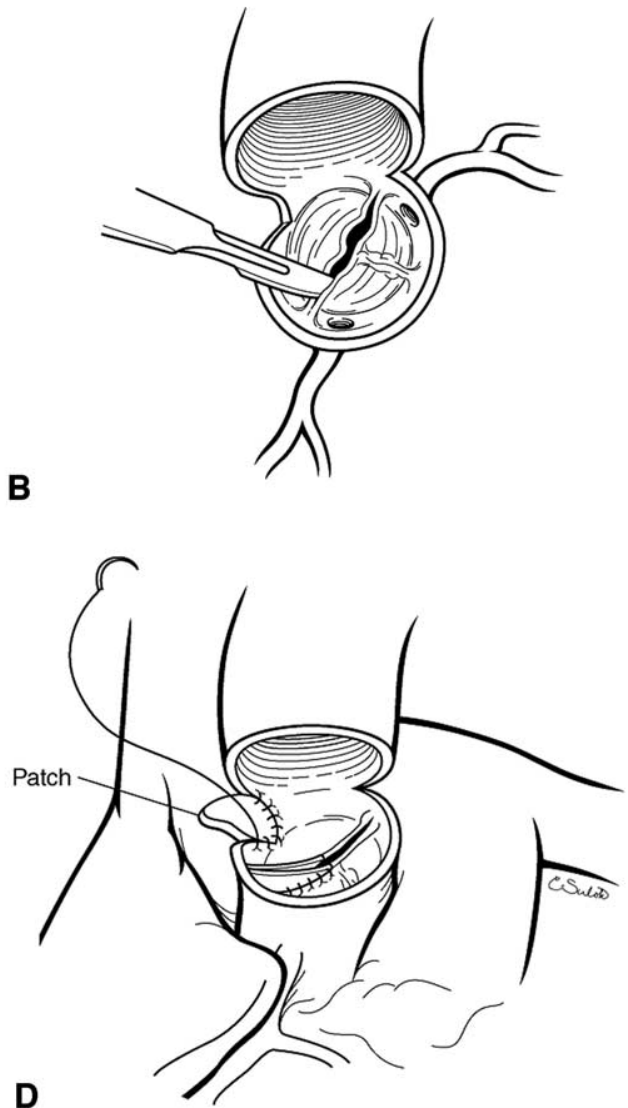

Figure 5. For patients with congenital AS with or without Al and an adequate annular dimension, we have developed a standardized technique. Transverse aortotomy is performed with extension into the noncoronary sinus of Valsalva (A). Commissural fusion is relieved, and leaflets are thinned of fibrous tissue (B). If adequate opening can be achieved with bicuspid valve, we do not proceed to divide rudimentary commissure or raphe. If despite adequate annular dimension, completion of commissurotomy does not result in adequate opening of bicuspid valve, rudimentary commissure or raphe is opened as well to recreate three-leaflet valve. To prevent prolapse, leaflets are supported by commissuroplasty, as described by Monro and colleagues. ${ }^{11}$ Small triangular patches of pericardium are used to prevent prolapse and reconstruct commissures without recreating stenosis (C). Finally, supravalvular aortic region is augmented as part of aortotomy closure to relieve any degree of supravalvular aortic narrowing such as commonly occurs with congenital AS (D).

5-year freedom from reintervention, identical to our findings with complex aortic valve repair. ${ }^{21}$ Although homograft replacement of the aortic root avoids creating a "two valve" problem, the durability is limited, and the freedom from reintervention was $82 \%$ in a recent series, again similar to the outcome with complex aortic valve repair. ${ }^{22}$ Mechanical valves carry an ongoing risk of thromboembolic complications, and replacement early in life places children at risk for a prolonged period. ${ }^{3}$ Placement of mechanical valves in small children often requires extensive annular enlargement to accommodate an adequate prosthesis; this enlargement may be more extensive than that required for an autograft or homograft and may result in late left ventricular dysfunction. ${ }^{23}$ In light of the imperfect choices for valve replacement in children, it would seem desirable to avoid valve replacement at the expense of acceptable residual lesions.

\section{Limitations}

This was a retrospective analysis through a long period. Indications for surgical intervention on the aortic valve have changed, as have aortic valve replacement options, techniques of repair, and available materials. We compared patients undergoing aortic valve repair with a contemporary but varied group of patients undergoing aortic valve replacement. We did not have a large enough group undergoing aortic valve replacement to stratify according to type of prosthesis. Although it may be invalid to compare valve repair with valve replacement prostheses that are no longer used or are considered less than ideal, there is no consensus 
in the literature regarding the best aortic valve replacement option in children. In the era of the Ross procedure, there continue to be proponents for mechanical valve replacement in children. Furthermore, the comparison with valve replacement is but one result of this study, and ultimately the results of complex aortic valve repair, such as early and late mortality and freedom from reintervention, must be assessed on their own. Although we could not identify a difference in freedom from reintervention between complex aortic valve repair and aortic valve replacement, the curves do diverge between 5 and 10 years. It is quite possible that if we had had more patients, this divergence would have reached significance.

\section{Conclusions}

Complex aortic valve repair achieves intermediate outcomes similar to those of aortic valve replacement. Further studies are required to determine long-term outcomes and to better identify candidates for valve repair. At present it would seem prudent to consider valve repair for patients with an adequate aortic annular dimension, without extensive leaflet destruction, and with the potential for a satisfactory result with a minimum of prosthetic material.

\section{References}

1. Fiane AE, Lindberg HL, Saatvedt K, Svennevig JL. Mechanical valve replacement in congenital heart disease. J Heart Valve Dis. 1996;5: $337-42$.

2. Solymar L, Rao PS, Mardini MK, Fawzy ME, Guinn G. Prosthetic valves in children and adolescents. Am Heart J. 1991;121:557-68.

3. Kvidal P, Bergstrom R, Malm T, Stahle E. Long-term follow-up of morbidity and mortality after aortic valve replacement with a mechanical valve prosthesis. Eur Heart J. 2000;21:1099-111.

4. Stewart S, Cianciotta D, Alexson C, Manning J. The long-term risk of warfarin sodium therapy and the incidence of thromboembolism in children after prosthetic cardiac valve replacement. $J$ Thorac Cardiovasc Surg. 1987;93:551-4.

5. Barratt-Boyes BG, Roche AH, Subramanyan R, Pemberton JR, Whitlock RM. Long-term follow-up of patients with the antibiotic-sterilized aortic homograft valve inserted freehand in the aortic position. Circulation. 1987;75:768-77.

6. Lupinetti FM, Duncan BW, Lewin M, Dyamenahalli U, Rosenthal GL. Comparison of autograft and allograft aortic valve replacement in children. J Thorac Cardiovasc Surg. 2003;126:240-6.

7. Laudito A, Brook MM, Suleman S, Bleiweis MS, Thompson LD, Hanley FL, et al. The Ross procedure in children and young adults: a word of caution. J Thorac Cardiovasc Surg. 2001;122:147-53.

8. de Sa M, Moshkovitz Y, Butany J, David TE. Histologic abnormalities of the ascending aorta and pulmonary trunk in patients with bicuspid aortic valve disease: clinical relevance to the Ross procedure. J Thorac Cardiovasc Surg. 1999;118:588-94.

9. Trusler GA, Moes CA, Kidd BS. Repair of ventricular septal defect with aortic insufficiency. J Thorac Cardiovasc Surg. 1973:66:394-403.

10. Yacoub MH, Khan H, Stavri G, Shinebourne E, Radley-Smith R. Anatomic correction of the syndrome of prolapsing right coronary aortic cusp, dilatation of the sinus of Valsalva, and ventricular septal defect. $J$ Thorac Cardiovasc Surg. 1997;113:253-61.

11. Tolan MJ, Daubeney PE, Slavik Z, Keeton BR, Salmon AP, Monro JL. Aortic valve repair of congenital stenosis with bovine pericardium. Ann Thorac Surg. 1997;63:465-9.
12. Cosgrove DM, Rosenkranz ER, Hendren WG, Bartlett JC, Stewart WJ. Valvuloplasty for aortic insufficiency. J Thorac Cardiovasc Surg. 1991;102:571-7.

13. Rowlatt UF, Rimoldi HJ, Lev M. The quantitative anatomy of the child's heart. Pediatr Clin North Am. 1963;10:499-518.

14. Duran C, Kumar N, Gometza B, al Halees Z. Indications and limitations of aortic valve reconstruction. Ann Thorac Surg. 1991;52:447-54.

15. Kalangos A, Beghetti M, Baldovinos A, Vala D, Bichel T, Mermillod B, et al. Aortic valve repair by cusp extension with the use of fresh autologous pericardium in children with rheumatic aortic insufficiency. J Thorac Cardiovasc Surg. 1999;118:225-36.

16. Ahn H, Kim KH, Kim YJ. Midterm result of leaflet extension technique in aortic regurgitation. Eur J Cardiothorac Surg. 2002;21:465-9.

17. Moore M. Pericardial tissue stabilized by dye-mediated photooxidation: a review article. J Heart Valve Dis. 1997;6:521-6.

18. Keane JF, Driscoll DJ, Gersony WM, Hayes CJ, Kidd L, O'Fallon WM, et al. Second natural history study of congenital heart defects. Results of treatment of patients with aortic valvar stenosis. Circulation. 1993;87(Suppl 1):I16-27.

19. Mitchell BM, Strasburger JF, Hubbard JE, Wessel HU. Serial exercise performance in children with surgically corrected congenital aortic stenosis. Pediatr Cardiol. 2003;24:319-24.

20. Marino BS, Bridges ND, Paridon SM. Aortic insufficiency: indications for surgery in children. Semin Thorac Cardiovasc Surg Pediatr Card Surg Annu. 1998;1:147-56.

21. Hraska V, Krajci M, Haun Ch, Ntalakoura K, Razek V, Lacour-Gayet F, et al. Ross and Ross-Konno procedure in children and adolescents: mid-term results. Eur J Cardiothorac Surg. 2004;25:742-7.

22. Mitchell MB, Campbell DN, Bishop DA, Clarke DR. Aortic allografts for left ventricular outflow tract replacement in children. Semin Thorac Cardiovasc Surg Pediatr Card Surg Annu. 2000;3:153-64.

23. Sharma GK, Wojtalik M, Siwinska A, Mrozinski B, Pawelec-Wojtalik M, Bartkowski R, et al. Aortoventriculoplasty and left ventricle function: long-term follow-up. Eur J Cardiothorac Surg. 2004;26:129-36.

\section{Discussion}

Dr Winfield J. Wells (Los Angeles, Calif). I want to ask you a series of questions, and these questions are designed to ferret out whether the data in this study prove beyond a reasonable doubt that complex valve repair provides a durable and effective alternative to replacement.

I just want to start out with a little housekeeping. You know all of us have had kids who have hung around for a while, but there are some 36-year-old patients in this study, so I was just wondering why these older patients were included.

Dr Tweddell. As stated, this is a retrospective analysis of aortic valve surgery at the Children's Hospital of Wisconsin, and there were some adult patients with congenital heart disease who came back for reintervention. I can't recall precisely how many were older than 18 years, but I think there were relatively few patients in that group.

Dr Wells. Okay, I suggest they might be eliminated if the title of the article is going to remain the same.

The second thing is you sort of tried to set up some question as to the best method for valve repair in children, at least in the article. But do you think there is really a question about the most effective method for valve replacement in children?

Dr Tweddell. The ideal valve replacement option in a child is still an open question.

Dr Wells. Correct. If somebody has a normal pulmonary valve, is there still a question in your mind whether the Ross is the best procedure for valve replacement?

Dr Tweddell. That decision is best left up to the patient and their family, and I would present them with the facts. In an infant 
or small child, certainly the Ross procedure is the best alternative, but these patients are very likely to require additional intervention directed at the autograft during their lifetimes. It is not going to be a lifelong solution for them. In the older child, closer to adult age and size, the best replacement option is still debatable. If you do a Ross procedure in a teenage patient and you end up ultimately having to go back and re-replace the autograft, then you have really added to their lifelong health burden. The patient not only has a mechanical valve in the aortic position but has a homograft and all the problems associated with a homograft, such as the questions of durability and immune consequences. Therefore in the older child, there remains a choice about the best option for valve replacement.

Dr Wells. I have a semantic question about the word "durability." In your title you suggest that repair provides a durable and effective alternative, so you know the question of durability really comes up when you look at your data. There is a real downturn in the effectiveness of this operation between 5 and 10 years. Would you agree with that?

Dr Tweddell. That is a very good question, Dr Wells. More and more we have been asked to perform valve repairs on patients with various forms of aortic valve pathology, and that compelled us to look at this group in great detail. I wanted to know whether we were doing the right thing. There does appear to be some divergence in the freedom from reintervention between valve replacement and complex repair between 5 and 10 years of followup, but we have relatively few patients out that far. With more patients, and assuming the current trend persisted, that could reach significance. Alternatively, the trend might diminish with increasing numbers. The fact remains that there was not a significant difference. I would add that once a valve is replaced, a patient is really started on a whole different line of potential problems and reinterventions, with a whole new hazard function and survival curve. Our data suggest it is reasonable to attempt valve repair in some cases, because it results in a duration of effective valve function that is not different from aortic valve replacement.

Dr Wells. I would suggest that it is some unusual quirk of statistical analysis that the difference between $48 \%$ and $77 \%$ is not statistically significant. I mean, it has to be some quirk. I would also suggest that really what you want to be looking at is the difference between the durability of your repairs. I know not all were done in the current era, but if we looked in the current era, would it be any different do you think, the current era versus the older?
Dr Tweddell. Actually it looks much more favorable in the current era, specifically in the last 10 years.

Dr Wells. I think I am trying to suggest that the $48 \%$, much of which I think represents the current era, really needs to be taken in the context of the kind of results that we have in our institution with more than 120 Ross procedures in children, where the freedom from reintervention at 12 years is $88 \%$. So there probably is a statistical difference between $48 \%$ and $88 \%$, but meanwhile, to get more civil, congratulations. It was a lot of work to do this study, and it provides some very nice benchmark data for us. Thank you for coming and presenting it to us.

Dr Tweddell. Yours are outstanding results, and better than those reported in the literature for the Ross procedure in the pediatric age group, where the 5-year freedom from reintervention is $85 \%$. I am not here to argue that the Ross procedure is not reasonable choice, but I think few would disagree that valve replacement should be deferred if a reparative procedure with similar hemodynamic outcome and freedom from reintervention were available. Our experience here is an initial attempt to look at that alternative.

Dr Ross Ungerleider (Portland, Ore). I think you need to be thanked for reminding us to think about valve repair when we encounter children who need aortic valve surgery, but one of the real advantages of the aortic valve autograft that you didn't mention but that we have seen in the patients in our series is that they can return to an essentially normal lifestyle. This really improves their development and their interaction with their peer group as they grow up, and I would doubt that you get the same kind of hemodynamic results from a valve repair. Have you looked at the exercise hemodynamics and the limitations that these children have compared with those in your aortic valve autograft series?

Dr Tweddell. Actually, I didn't, but it has actually been looked at. One of our newer faculty members, Dr Janette Strasburger, who came to us from Northwestern, looked at that question. She and her colleagues found that patients with a mean gradient less that 50 $\mathrm{mm} \mathrm{Hg}$ and with mild residual AS after repair of AS, Ross procedure, or valvotomy or with no repair had normal exercise endurance. I will also add that current recommendations would exclude patients who have a right ventricular to pulmonary artery conduit in place from some sports. Therefore I am not certain that activity restrictions for patients after successful aortic valve repair with mild residual stenosis or insufficiency would be substantially different from restrictions after the Ross procedure. 